\title{
Experimental and Finite Element Analysis of failure of Sheet Molding Compound (SMC) and Steel Insert Joint
}

\author{
Ketan Kulkarni ${ }^{*}$, Gautam Ranjan ${ }^{2}$ and S.R. Patil ${ }^{3}$ \\ ${ }^{13}$ Sinhgad Academy of Engineering, Kondhwa, Pune, Maharashtra, India \\ ${ }^{2}$ Tata Autocomp systems Ltd., Pune, India \\ Accepted 15 June 2016, Available online 20 June 2016, Special Issue-5 (June 2016)
}

\begin{abstract}
The use of SMC (Sheet Molding Compound) has regained a renewed interest from the automotive industry over the last years. SMC is a thermoset polymer glass fiber matrix compound widely used for manufacturing automotive parts, sub-structural components. This work is concerned with understanding the concept of compounding of SMC sheets, concept of compression molding process, post-molding processes and mathematical investigation of maximum bearable pullout force for the failure of sheet molding compound and steel insert joint. The actual experiment, pullout test was done on universal testing machine and average maximum pullout force found out. The safe limit of pullout force is set by industry standards equal to 300N. The experiment results showed maximum pullout force equal to 1869.34N. Finite element analysis was done using CAE tool on four FE models and the results are compared.
\end{abstract}

Keywords: SMC, compression molding, post-molding, pullout force.

\section{Introduction}

SMC, as a thermoset compound is selected because of its high thermal stability and it has lower coefficient of thermal expansion than steel. A fundamental advantage of the high thermal stability is the proven online paint ability. Harbers et al. described that flexibility, lower tooling costs, design freedom, integration of functions and low weight are additional factors, which made SMC as a material of choice. Sheet molding compounds belong to the family of composites. It is made from a thermoset polymer matrix reinforced by short glass fibers around $25 \mathrm{~mm}$ long. SMC sheets are $2-3 \mathrm{~mm}$ thick which are preimpregnated with randomly distributed fibers. Then it follows with the creation of a stack which contained set of layers (3-10). SMC parts are formed by putting SMC charge (sheets)in a mould followed by compression molding. This allows rapid curing of the part at $150^{\circ} \mathrm{C}$. Corre and Orgeas described shear and compression behavior of SMC.

These materials are mainly used in the automotive industry for production of car body parts and semistructural parts. It has also found use in electrical engineering to make large-size enclosures and cabinets.

Choi and Park developed LPMC which has similar mechanical properties compared to conventional sheet molding compound (SMC) but excellent moldability due to the different thickening system. A crystalline polyester called Crystic impreg is used as a thickening agent instead of metal oxide in LPMC formulation. SMC and GMT are widely used fiber reinforce material in automobile body. Glass-fiber mat thermoplastic material is abbreviated as GMT. Yuxuan et al. studied impact properties of GMT. It has thermoplastic matrix and glass fiber framework and the molded GMT part is almost isotropic with $50-300 \mathrm{~N} / \mathrm{mm}^{2}$ strength. Shirinbayan and Fitoussi studied high strain rate tensile tests on Advanced SMC (A-SMC with 50\% glass fiber) which shows that the composite behavior is strongly strain-rate dependent although the Young's modulus remains constant for Randomly Oriented fibers (RO) and Highly Oriented fibers (HO) samples when strain rate increases.

\section{Composition of SMC}

SMC is a composite material contains various components as mentioned in table 1 .

Table 1: Composition of SMC

\begin{tabular}{|c|c|c|}
\hline Constituents & $\begin{array}{c}\text { Weight in } \\
\text { Percentage }\end{array}$ & Function \\
\hline Polystyrene & $11-13$ & $\begin{array}{c}\text { These are Reactive } \\
\text { monomers for cross } \\
\text { linking function }\end{array}$ \\
\hline Fiberglass & $\sim 30$ & Reinforcement \\
\hline $\begin{array}{c}\text { Unsaturated } \\
\text { Polyester }\end{array}$ & $10-16$ & $\begin{array}{c}\text { Acts as a Reactive } \\
\text { polymer }\end{array}$ \\
\hline $\begin{array}{c}\text { Calcium } \\
\text { carbonate }\end{array}$ & $\sim 40$ & $\begin{array}{c}\text { Acts as a Filler in } \\
\text { matrix }\end{array}$ \\
\hline
\end{tabular}




\begin{tabular}{|c|c|c|}
\hline $\begin{array}{c}\text { Magnesium } \\
\text { oxide }\end{array}$ & $0.5-0.7$ & $\begin{array}{c}\text { Increases viscosity } \\
\text { during manufacturing } \\
\text { process }\end{array}$ \\
\hline Zinc stearate & $1.0-2.4$ & Lubricant \\
\hline
\end{tabular}

\section{Compounding or manufacturing of SMC sheets}

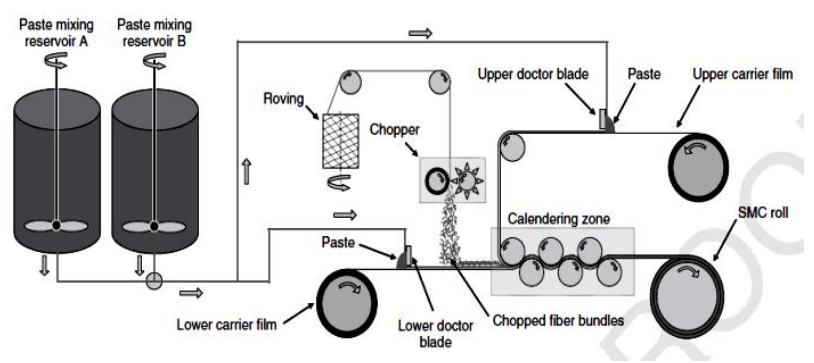

Figure 1: Operation of compounding of SMC sheets.

The compounding process is a continuous operation where several steps can be classically different. The ingredients for making paste are first mixed together. Using a specially designed compound machine, this paste is allowed to spread onto a conveyor which carries polymeric film. Then discontinuous fibers 25 $\mathrm{mm}$ long are distributed onto the paste layer. This operation forms a dry bed, also called mat of fibers which is subsequently sandwiched between another carrier film and layer of paste. Fig.1. shows operation of compounding of SMC sheets.

\section{Molding Process}

Composite fabrication usually involves the process of wetting, mixing or saturating the reinforcement with the matrix. The matrix is then bound together (with heat or a chemical reaction) into a rigid structure. The operation is usually done in an open or closed forming mold. The order as well as ways of introducing the ingredients varies considerably. The fabrication methods are as follows:
1) Compression molding
2) Vacuum bag molding
3) Pressure bag molding
4) Autoclave molding
5) Resin transfer molding
6) Pultrusion molding
7) Thermoplastic molding

\section{Compression molding}

Compression molding was first developed to manufacture composite parts for metal replacement applications. It is typically used to make larger flat or moderately curved parts. This method of molding is greatly used in manufacturing automotive parts such as hoods, side walls, fenders, spoilers, scoops, bumpers as well as smaller more complex parts.

The material to be molded is placed in the mold cavity and the heated platens (core and cavity) are closed by a hydraulic ram. Sheet molding compounds (SMC) or Bulk molding compounds (BMC) are conformed to the mold form by the applied pressure and heated with steam until the curing reaction occurs. SMC charge or sheet is weighed and cut to conform to the surface area of the mold. The mold is then cooled and the part removed. Fig.2a. shows flow diagram of compression molding process. The charge may be loaded onto the mold cavity either in the form of pellets or sheets or may be loaded from a plasticating extruder. The charge is heated above melting point, formed and cooled. Less flow orientation occurs during the compression stage if the feed material is distributed evenly over the mold surface. In compression molding there are six important considerations.

1) Determining the proper amount of feed material.

2) Determining the minimum time required to heat the material.

3) Determining the minimum amount of energy required to heat the material.

4) Determining the appropriate heating technique.

5) Determining the required force to ensure that charge attains the proper shape.

6) Designing the mold for rapid cooling when the material has been compressed into the mold.

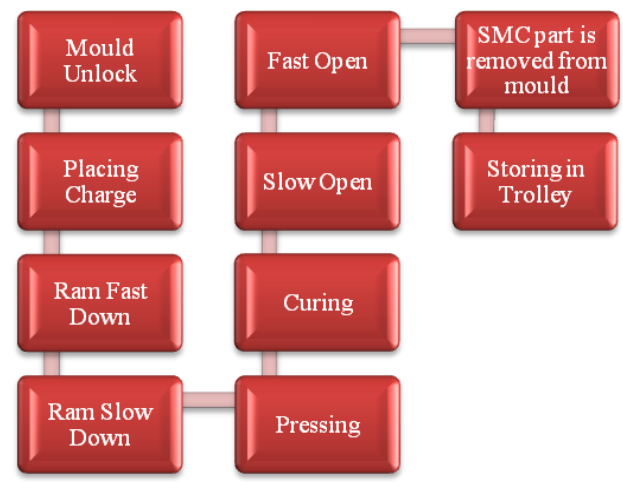

Figure 2a: Flow diagram of compression molding process

\section{Post-molding process}

The post-molding process is the process done on the SMC part removed from the mold. The post-molding processes include: Deflashing and filing, putty-filling, inner sanding and outer sanding. Fig $2 \mathrm{~b}$. shows flow diagram of post-molding processes.

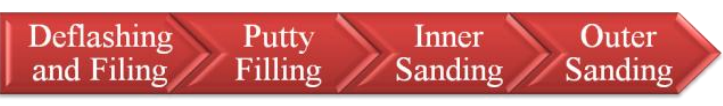

Figure 2b. Flow diagram of Post-molding processes.

1) Deflashing and Filing: This is the first post-molding process in which flashes are removed from the molded SMC part by conventional cutter and then filing is done to remove marks of ejector pins. 
2) Putty filling: After filing, putty is filled on the each corner of SMC part.

3) Inner sanding: Sanding is done by sand paper on inner side first to remove the markings on the molded part.

4) Outer sanding: Outer surface is subjected to sanding same as inner surface.

\section{Study objective}

Mathematical investigation of maximum pullout force and finite element analysis for the failure of Sheet Molding Compound (SMC) and steel insert joint.

\section{Scope}

1.Experimental analysis of SMC and steel insert joint 2.Simulation of pullout test of various $\mathrm{FE}$ models in $\mathrm{CAE}$ 3.Comparison of results and find the best $\mathrm{FE}$ model.

\section{Experimental Setup}

Tensile properties of the SMC samples were determined following the standard procedure described in ASTM D638 with type I specimens. The universal testing machine (INSTRON UTM) was operated at a crosshead speed of $5 \mathrm{~mm} / \mathrm{min}$ which was interfaced with a computer. A bolt was fastened in the tapped hole of an insert and other end of bolt was fixed in crosshead. The pullout test was done at room temperature and six runs were made to find the average as shown in fig 3.

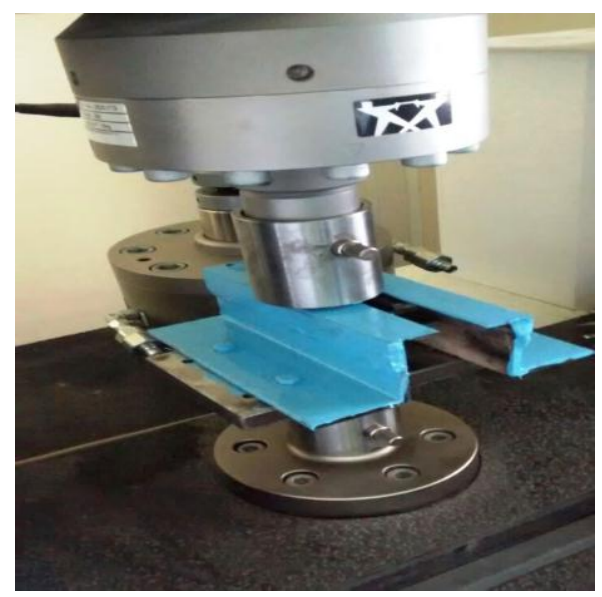

Figure 3 Pullout test on INSTRON UTM

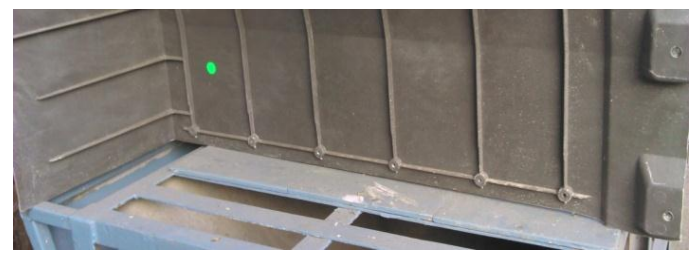

Figure 4a. SMC side panel
Fig.4a. and fig.4b. showed SMC side panel with six joints of SMC boss and steel insert. One by one each sample was tested. The maximum pullout force for the failure of these joints was obtained. The pullout test was destructive test which allowed failure analysis of automotive joint.

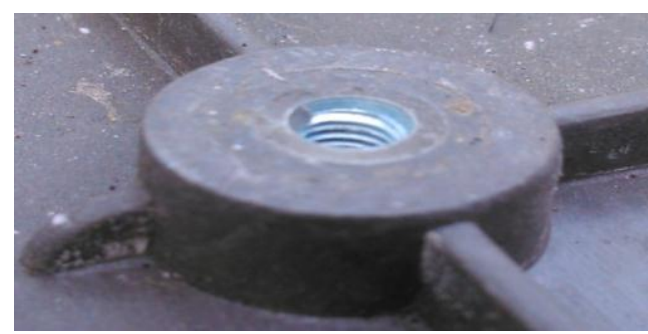

Figure 4b. SMC boss and steel insert joint

\section{Experimental Results}

The pullout test results obtained as shown in graph 1 . which showed that for each sample, the force first increased linearly with extension. Then the force increased nonlinearly and attained maximum value. At the maximum value of force, SMC failed in shear and thus force reduced.

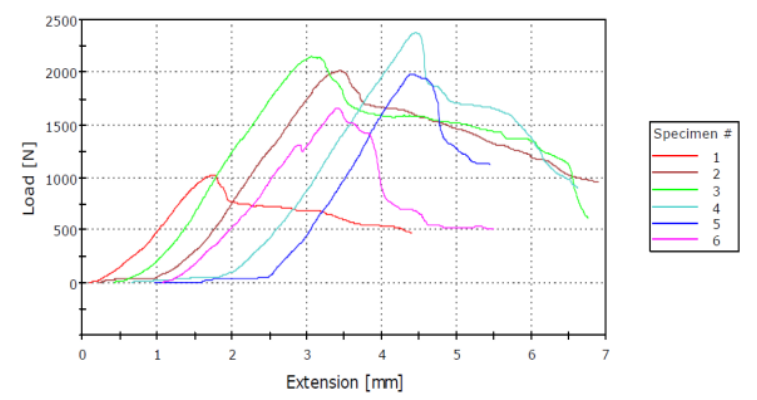

Graph 1 Load (N) versus extension (mm) for six samples.

Table 2 Experimental results

\begin{tabular}{|c|c|}
\hline Sample No. & Maximum Load (N) \\
\hline 1 & 1030.49 \\
\hline 2 & 2012.89 \\
\hline 3 & 2149.27 \\
\hline 4 & 2377.22 \\
\hline 5 & 1985.43 \\
\hline 6 & 1660.76 \\
\hline
\end{tabular}

Table 2 shows the values of maximum pullout force for six samples. Average value of the maximum pullout force $=1869.34 \mathrm{~N}$.

\section{Analytical Calculation}

\section{Material properties and dimensions}

Steel Insert:

Material : Steel (Young's Modulus $=2.1 \times 10{ }^{5} \mathrm{MPa}$ ) 
1. Density : $7900 \mathrm{~kg} / \mathrm{m}^{3}$

2. Length $=10.171 \mathrm{~mm}$

3. Inner Diameter $=5 \mathrm{~mm}$ (M5 threaded hole)

4. Outer Diameter $=9 \mathrm{~mm}$

SMC Boss with ribs:

1. Material : Sheet molding compound (composite) (Young's Modulus= $9500 \mathrm{MPa}$ )

2. Density : $1900 \mathrm{~kg} / \mathrm{m}^{3}$

3. Length $=11 \mathrm{~mm}$

4. Inner Diameter $=9 \mathrm{~mm}$

5. Outer Diameter $=18 \mathrm{~mm}$

6. Rib thickness $=1 \mathrm{~mm}$

7. Base surface thickness $=1.5 \mathrm{~mm}$

The pullout force on steel insert in the experiment induces shearing of the SMC material[9]. Thus failure mechanism for SMC boss and steel insert joint is shear. The shear stress at the interface of SMC and steel insert joint is calculated as in eq.(1):

$$
\begin{gathered}
\text { Shear stress }(\tau)=\frac{\text { Shear Force }(\mathrm{F})}{\text { Shear Area }(\mathrm{A})} \\
\tau=\frac{\mathrm{F}}{\pi \times \mathrm{d} \times \mathrm{t}} \\
\tau=\frac{1869.24}{2 \times(\pi \times 9 \times 1.7)} \\
\tau=19.445 \mathrm{MPa}
\end{gathered}
$$

\section{Finite Element Method}

Finite element method has now become an integral part of Computer Aided Engineering (CAE). It is extensively used in the analysis of many complex reallife systems. It is evolved as an extension of numerical analysis using matrix methods of structural analysis and was initially perceived as a tool for structural analysis alone. Its applications now cover structures, bio-mechanics as well as electromagnetic field problems. Simple linear static problems as well as highly complex non-linear transient dynamic problem are effectively solved using finite element method. The field of finite element analysis has grown and now tests on rigorous mathematical foundation. Many powerful commercial packages are now available enabling its widespread use in several industries.

The pullout test was simulated using FEM preprocessor HyperMesh 13.0, solver optistruct and postprocessor Hyperview 13.0. Finite element analysis (FEA) was done on four FE models:

1.SMC boss with 2 ribs and plain cross-section steel insert joint.

2.SMC boss without ribs and standard steel insert joint

3.SMC boss with 2 ribs and standard steel insert joint.

4.SMC boss with 4 ribs and standard steel insert joint.

\section{Analysis of SMC boss with 2 ribs and plain cross-} section steel insert joint

\section{Step 1 Import/edit geometry}

The required geometry for analysis is imported into Hypermesh 13.0 in standard IGES format as shown in fig.5a. The imported geometry is edited in Hypermesh. Fig.5b. shows sectional front view to describe cross section of insert.

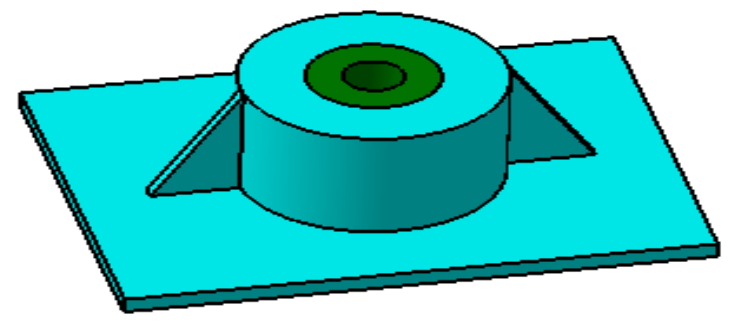

Figure 5a. IGES format

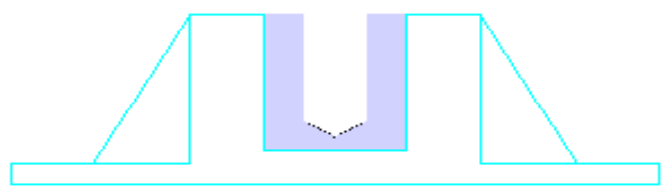

Figure 5b. Sectional front view

\section{Step 2 Meshing}

Once the geometry is appropriately edited, a mesh is created to approximate the geometry. A solid 3D mesh is created, with element size of $2 \mathrm{~mm}$ to approximate SMC boss and steel insert.1 D RBE3 elements are created and at independent node force is applied. The specification of mesh is as follows:-element size:- $2 \mathrm{~mm}$, solid elements:- CTETRA (tetra4). Fig.6 shows finite element (FE) model of SMC boss with two ribs and plain cross-section steel insert.

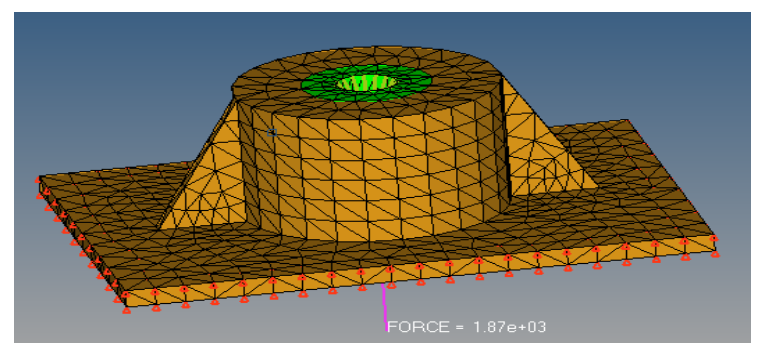

Figure 6. FE model

\section{Step 3 Material and Property information}

After meshing, material (e.g. Young's Modulus, density, etc.) and property information (e.g. thickness values) are assigned to the element. Material of boss:- SMC, density of SMC: $-1900 \mathrm{~kg} / \mathrm{m}^{3}$, Young's modulus:9500MPa, Poisson's ratio:-0.3 Material of insert:- Steel, 
Density of steel:- $7900 \mathrm{~kg} / \mathrm{m}^{3}$, Young's modulus:-2.1 $\times 10^{5} \mathrm{Mpa}$, Poisson's ratio: -0.3

\section{Step 4 Load, constraints and solver information}

The pullout force is applied at the independent node of $1 \mathrm{D}$ RBE3 elements equal to $1870 \mathrm{~N}$ vertically upward in $\mathrm{Z}$ direction. All sides of the base surface are constrained in all 6 degrees of freedom. The analysis is run in OptiStruct solver.

\section{Step 5 Post-processing/ results}

Once the solution has ended successfully, the postprocessing of the simulation results is done in HyperView contour plots. Stresses and deformations are plotted and examined. The following results are obtained for displacement as shown in fig.7a. and stresses are shown in fig.7b. and fig7c.Shear stress at the SMC boss and insert interface: Calculated Result = 19.45 $\mathrm{MPa}$,Simulation Result $=20.05 \mathrm{MPa}$ Error $=3.08$ $\%$ Since error is less than $5 \%$, it is acceptable.

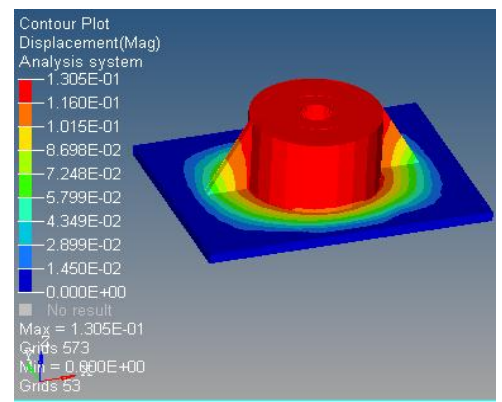

Figure 7a. Displacement (Maximum value $=0.1305 \mathrm{~mm}$ ) Maximum displacement is $0.1305 \mathrm{~mm}$ which is on the top side of SMC boss.

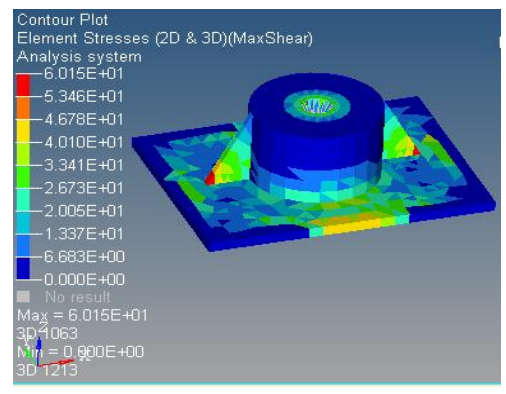

Figure 7b. Shear stress(maximum value $=60.15 \mathrm{MPa}$ )

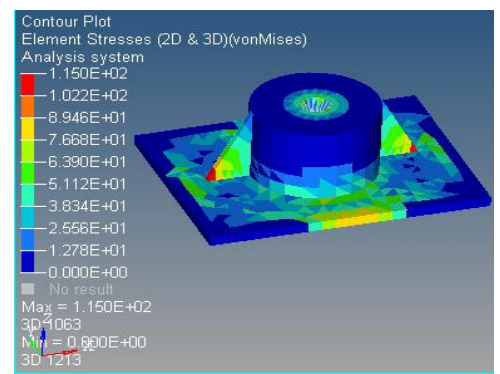

Figure 7c. VonMises stress(maximum value=115 $\mathrm{MPa}$ )
Maximum value of vonMises stress obtained is 115 $\mathrm{MPa}$, which exceeds the tensile strength of SMC i.e. 60$80 \mathrm{MPa}$, thus failure occurs at the ribs end. The ribs are provided for even stress distribution and strengthening the design.

\section{Analysis of SMC boss without ribs and standard steel insert joint}

\section{Step 1 Import/edit geometry}

The required geometry for analysis is imported into Hypermesh 13.0 in standard IGES format as shown in fig.8a. The imported geometry is edited in Hypermesh. Fig.8b. shows sectional front view to describe cross section of standard insert.

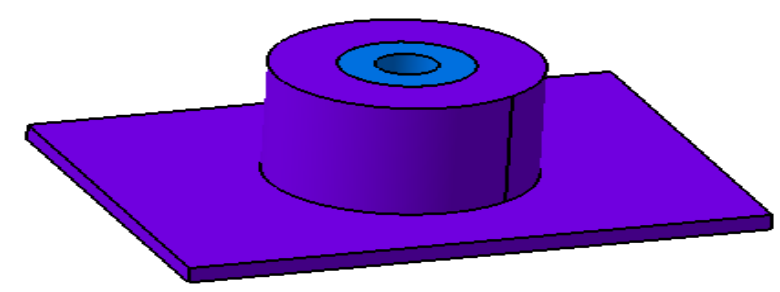

Figure 8a. IGES format

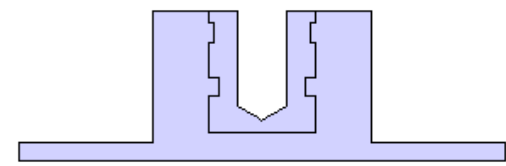

Figure 8b. Sectional front view

\section{Step 2 Meshing}

Once the geometry is properly edited, a mesh is created to approximate the geometry. A solid 3D mesh is created, with element size of $2 \mathrm{~mm}$ to approximate SMC boss and standard steel insert.1 D RBE3 elements are created and at independent node force is applied. The specification of mesh is as follows:-element size:2mm, solid elements:- CTETRA (tetra4). Fig.9a. shows finite element (FE) model of SMC boss without ribs and standard steel insert. Fig.9b. shows Wireframe model showing detailed representation of RBE3 elements and point of application of force.

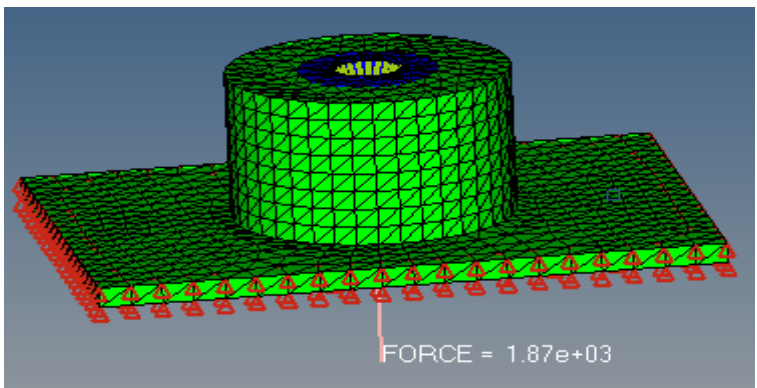

Figure 9a. FE model 


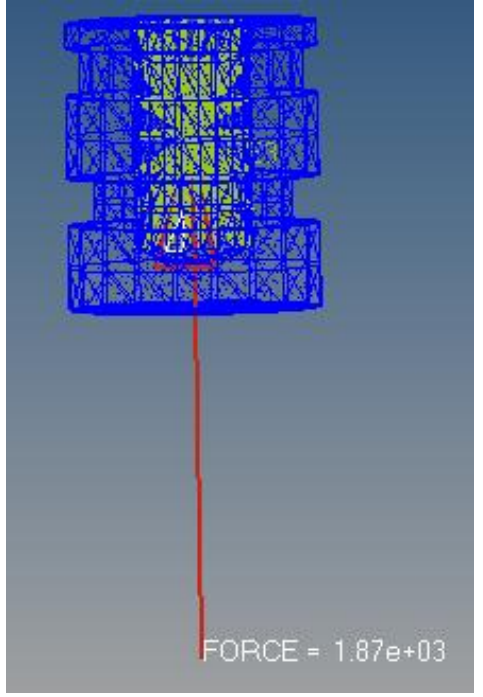

Figure 9b. Wireframe model showing standard insert, RBE3 elements and point of application of force.

\section{Step 3 Material and Property}

After completion of meshing, material (e.g. Young's Modulus, density, etc.) and property information (e.g. thickness values) are assigned to the element. Material of boss:- SMC, density of SMC: $-1900 \mathrm{~kg} / \mathrm{m}^{3}$, Young's modulus:- 9500MPa, Poisson's ratio:-0.3 Material of insert:- Steel, Density of steel:- $7900 \mathrm{~kg} / \mathrm{m}^{3}$, Young's modulus:- $2.1 \times 10^{5} \mathrm{Mpa}$, Poisson's ratio:-0.3

\section{Step 4 Load, constraints and solver information}

The pullout force is applied at the independent node of 1 D RBE3 elements equal to $1870 \mathrm{~N}$ vertically upward in $\mathrm{Z}$ direction. All sides of the base surface are constrained in all 6 degrees of freedom. The analysis is run in OptiStruct solver.

\section{Step 5 Post-processing/ results}

The post-processing of the simulation results is done in HyperView contour plots. Stresses and deformations are plotted and examined. The following results are obtained for displacement as shown in fig.10a and for stresses as shown in fig.10b and fig.10c.

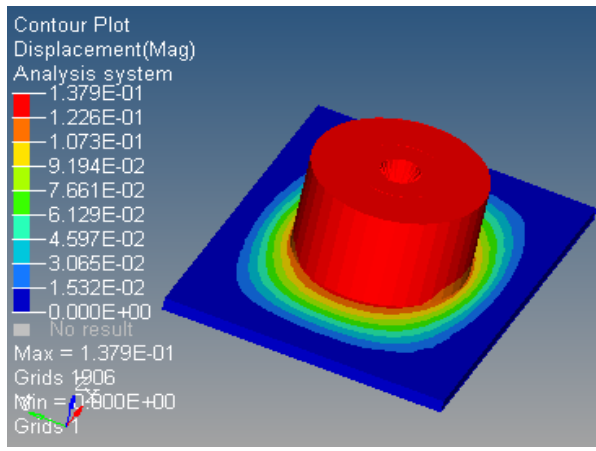

Figure 10a. Displacement (Maximum value $=0.1379 \mathrm{~mm}$ )

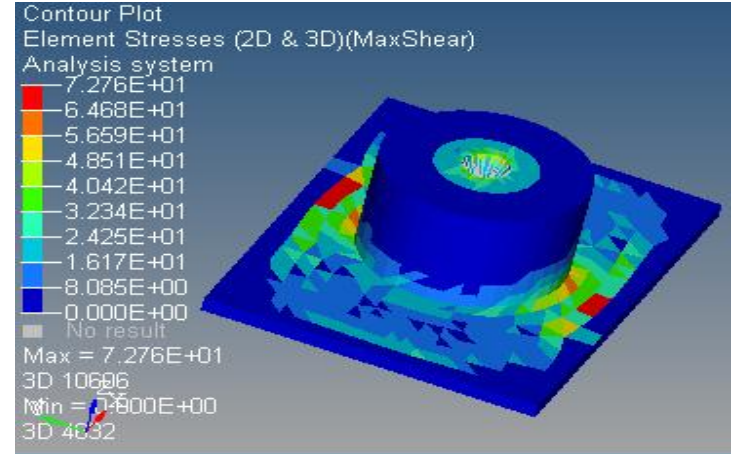

Figure 10b. Shear stress (maximum value=72.76 $\mathrm{MPa}$ )

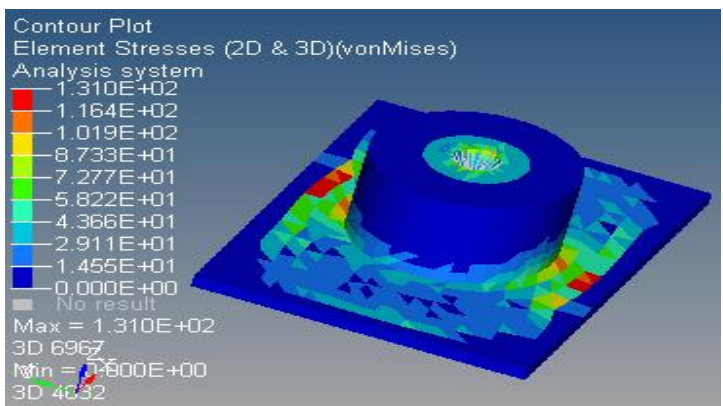

Figure 10c. vonMises stress(maximum value $=131$ $\mathrm{MPa})$

Maximum value of vonMises stress obtained is 131 $\mathrm{MPa}$, which exceeds the tensile strength of SMC i.e. 60$80 \mathrm{MPa}$, thus failure occurs on the SMC base surface. The value of the stress is higher due to absence of ribs. The ribs strengthens the design and are absent in this model.

\section{Analysis of SMC boss with 2 ribs and standard steel insert joint}

\section{Step 1 Import/edit geometry}

The required geometry for analysis is imported into Hypermesh 13.0 in standard IGES format as shown in fig.11. The imported geometry is edited in Hypermesh.

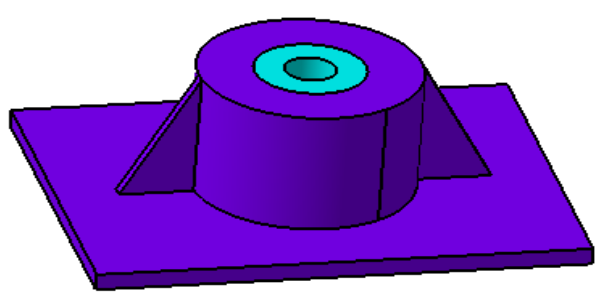

Figure 11. IGES format

\section{Step 2 Meshing}

The specification of mesh is as follows:-element size:2mm, solid elements:- CTETRA (tetra4). Fig.12. shows finite element (FE) model of SMC boss with 2 ribs and standard steel insert. 


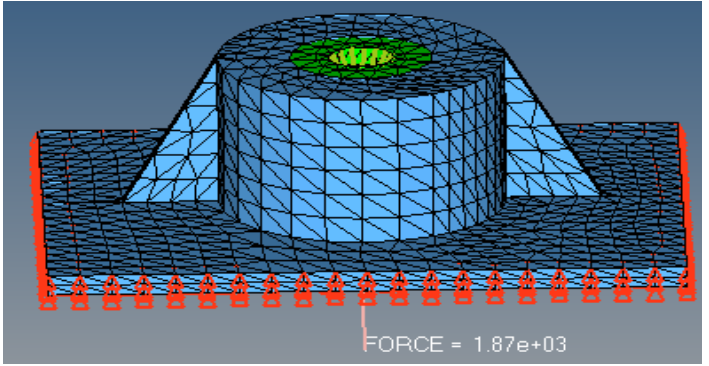

Figure 12. FE model

\section{Step 3 Material and property}

The material and property for SMC and standard steel insert are discussed earlier.

\section{Step 4 Load, constraints and solver information}

Load application and constraints are same as previous two FE models.

\section{Step 5 Post-processing/ results}

The following results are obtained for displacement as shown in fig.13a. and for stresses as shown in fig.13b and fig. 13c. Shear stress at the SMC boss and insert interface: Calculated Result $=19.45 \mathrm{MPa}$, Simulation Result $=18.50 \mathrm{MPa}$, Error $=4.88 \%$ Since error is less than $5 \%$, it is acceptable.

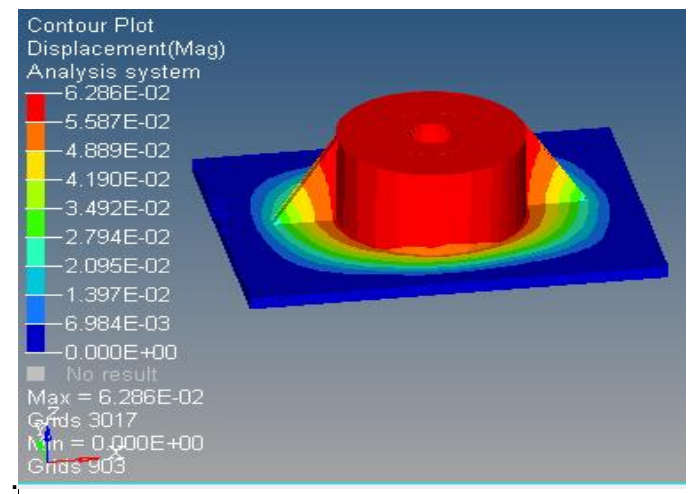

Figure 13a. Displacement (Maximum value $=0.06286 \mathrm{~mm}$ )

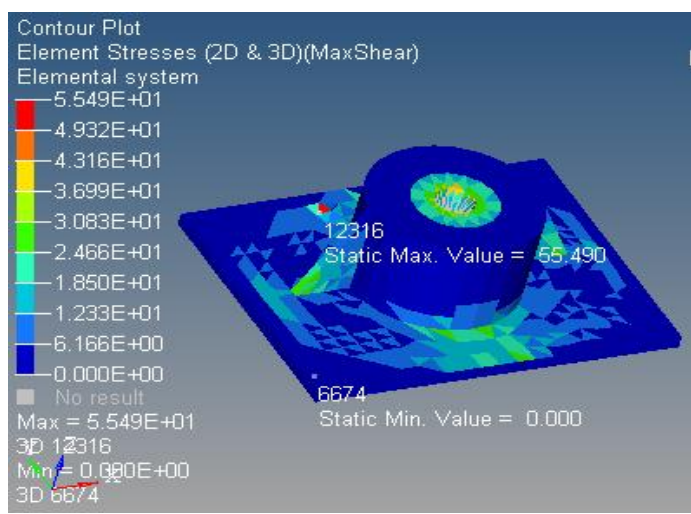

Figure 13b. Shear stress (maximum value=55.49 $\mathrm{MPa}$ )

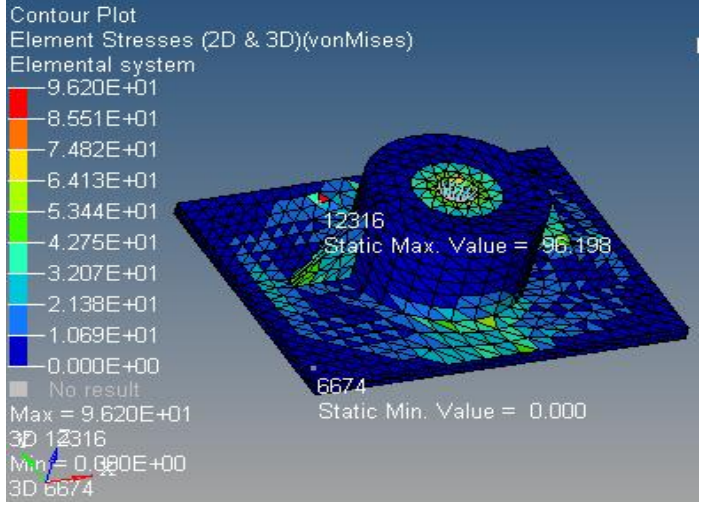

Figure 13c. vonMises stress (maximum value $=96.20$ $\mathrm{MPa})$

Maximum value of vonMises stress obtained is 96.20 $\mathrm{MPa}$, which exceeds the tensile strength of SMC i.e. 60 $80 \mathrm{MPa}$, thus failure occurs on the SMC base surface (as shown on element ID 12316). The value of the stress is lower than the previous two models due to presence of ribs and better design. The ribs strengthens the design and provide even distribution of stress.

\section{Analysis of SMC boss with 4 ribs and standard steel insert joint}

\section{Step 1 Import/edit geometry}

The required geometry for analysis is imported into Hypermesh 13.0 in standard IGES format as shown in fig.14. The imported geometry is edited in Hypermesh.

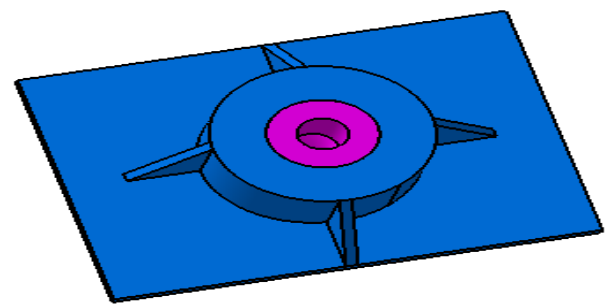

Figure 14. IGES format

\section{Step 2 Meshing}

The specification of mesh is as follows:-element size:2mm, solid elements:- CTETRA (tetra4). Fig.15a shows finite element (FE) model of SMC boss with 4 ribs and standard steel insert.

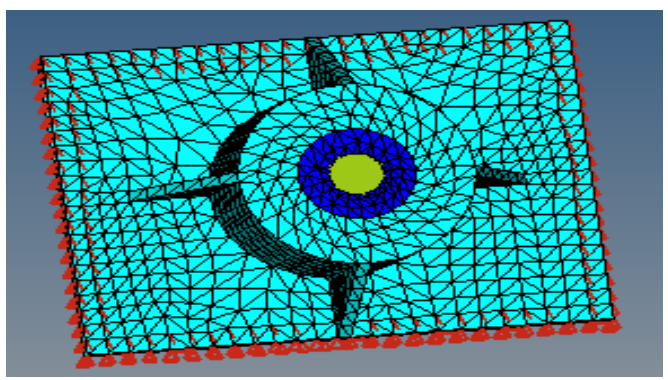

Figure 15a. FE model 


\section{Step 3 Material and property}

The material and property for SMC and standard steel insert are discussed earlier.

\section{Step 4 Load, constraints and solver information}

Load application and constraints are same as previous three FE models.

\section{Step 5 Post-processing/ results}

The following results are obtained for displacement as shown in fig.15b. and for stresses as shown in fig.15c and fig $15 \mathrm{~d}$. Shear stress at the SMC boss and insert interface: Calculated Result $=19.45 \mathrm{MPa}$, Simulation Result $=20.12 \mathrm{MPa}$, Error $=3.44 \%$ Since error is less than $5 \%$, it is acceptable.

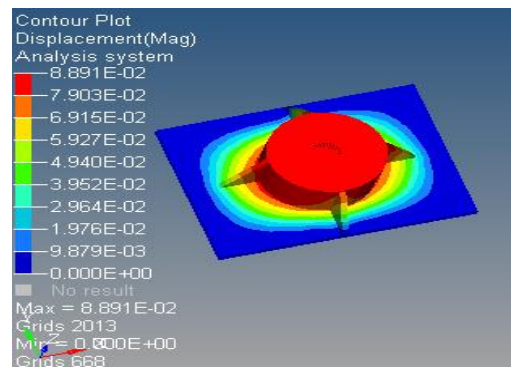

Figure 15b. Displacement (Maximum value $=0.08891 \mathrm{~mm}$ )

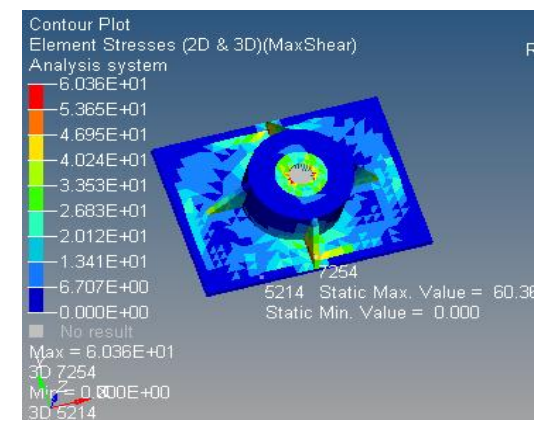

Figure 15c. Shear stress (maximum value=60.36 MPa)

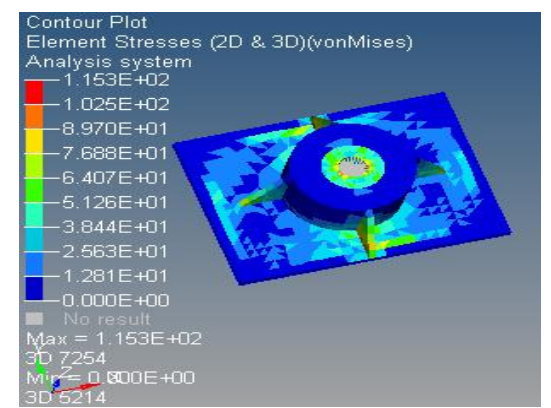

Figure 15d. Shear stress (maximum value=115.3 MPa)

Maximum value of vonMises stress obtained is 115.3 $\mathrm{MPa}$, which exceeds the tensile strength of SMC i.e. 60$80 \mathrm{MPa}$, thus failure occurs on the interface of SMC base surface and ribs.
The value of the stress is higher than that for FE model with two ribs due to stress is not evenly distributed in the region between the adjacent ribs this leads to sress concentration in the region of adjacent ribs.

\section{Comparison of Results}

Table 3: comparison of above FE models based on displacement and stresses

\begin{tabular}{|c|c|c|c|c|}
\hline 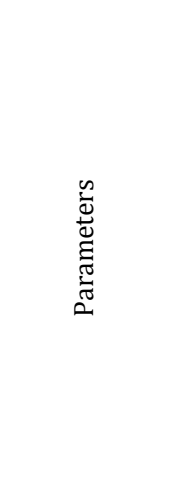 & 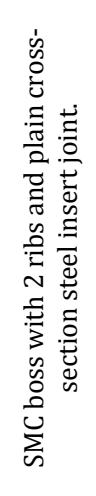 & 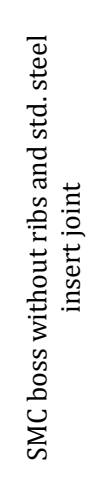 & 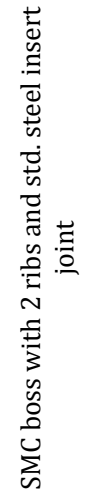 & 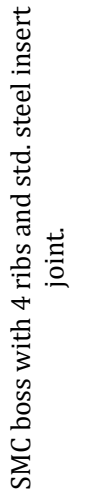 \\
\hline $\begin{array}{c}\text { Maximum } \\
\text { Displacement } \\
(\mathrm{mm})\end{array}$ & 0.1305 & 0.1379 & 0.0628 & 0.0889 \\
\hline $\begin{array}{l}\text { Maximum } \\
\text { Shear Stress } \\
\text { (MPa) }\end{array}$ & 60.15 & 72.76 & 55.49 & 60.36 \\
\hline $\begin{array}{c}\text { Maximum } \\
\text { VonMises } \\
\text { Stress (MPa) }\end{array}$ & 115 & 131 & 96.20 & 115.30 \\
\hline
\end{tabular}

The results of each FE model are compared and selected the best model for the same average pullout analysis. The table 3 describes the comparison of above FE models based on displacement and stresses. The tensile strength of SMC is ranging from 60 to $80 \mathrm{MPa}$ depending upon the grade of SMC. Those FE models are subjected to the critical stress are deformed plastically with crack formation.

\section{Conclusion}

The pullout test of SMC and steel insert joint was carried out on Universal Testing Machine according to procedure described in ASTM D638 with type I specimens. The average value of pullout force obtained experimentally is $1869.34 \mathrm{~N}$ which is greater than $300 \mathrm{~N}$ required as per Industry standards thus the joint is safe.

The average pullout force was used as input in CAE for four FE models and maximum value of displacement, shear stress and vonMises stress were obtained and compared. The Analytical and CAE results are approximately same with error less than $5 \%$. Maximum values of shear stress and vonMises stress on SMC boss with two ribs and standard steel insert joint are 55.49 MPa and 96.20 MPa respectively, which are lower than that of other FE models for the same 
applied force thus its design is better than other FE models. SMC boss with four ribs and standard steel insert joint has higher value of vonMises stress than that with two ribs because of stress concentration occurred in the region of adjacent ribs.

\section{References}

F. Harbers, Advances in SMC/BMC Automotive Applications, SAE paper 2002-01-2040.

Steven Le Corre, Laurent Orge'as,, Denis Favier, Ali Tourabi, Abderrahim Maazouz, $\mathrm{Ce}^{\prime}$ cile Venet, Shear and compression behavior of sheet molding compounds, Composites Science and Technology 62 (2002) 571-577.

Chi-Hoon Choi, Sang-Sun Park, Kye-Won Ahn , Jeong-Eek Rhee, Low Pressure Molding Compound Hood Panel for a Passenger Car, Seoul 2000 FISITA World Automotive Congress June 12-15, 2000, Seoul, Korea.
Yuxuan Li, Zhongqin Lin, Aiqin Jiang, G. Chen, Experimental study of glass-fiber mat thermoplastic material impact properties and lightweight automobile body analysis, Materials and Design 25 (2004) 579-585.

M. Shirinbayan, J. Fitoussi, F. Meraghni, B. Surowiec, M. Bocquet, A. Tcharkhtchi, High strain rate visco-damageable behavior of Advanced Sheet Molding Compound (A-SMC) under tension, Composites Part B 82 (2015) 30-41.

Fisk Martin, Damage level calculation in SMC composite structures, Master's thesis, 2006.

Herbert R. R. Martins, Marcus Zucchini,Ball Joint Pull Out Simulation using Finite Element Analysis, SAE paper 200601-2867.

Murilo Del Rio Duarte, H. Martins, Inner Joint Forming and Pullout Simulation Using Finite Element Analysis, SAE paper 2004-01-3422.

Ferdinand L. Singer, Andrew Pytel, Strength of materials, 4th edition,2009, pp155-180.

Seshu P.,A textbook of finite element analysis, eastern economy edition, 2012, pp145-231. 